\title{
CURRENT INTERNATIONAL TRENDS IN SEVERE ACUTE BRAIN TRAUMA
}

\author{
JULIO CRUZ*
}

\begin{abstract}
A comprehensive review is presented on current international trends regarding research and management of severe acute brain trauma. Controversial issues are thoroughly discussed and an attempt is made to clarify questionable aspects from pertinent publications in the international literature. A proposition is made to manage not only intracranial pressure and perfusion pressure, but also cerebral hemometabolic parameters in these critically ill patients. Currently available management guidelines are not evidence-based.
\end{abstract}

KEY WORDS: head injury, intracranial pressure, cerebral perfusion pressure, cerebral extraction of oxygen

\section{Tendências internacionais atuais em traumatismo cerebral agudo grave}

RESUMO - Uma revisão abrangente é apresentada referente a tendências internacionais atuais em pesquisa e tratamento do traumatismo cerebral agudo grave. Aspectos controversos são discutidos, e é feita tentativa de esclarecer pontos questionáveis da literatura internacional pertinente. Uma proposicão e feita para que sejam tratados nao somente a pressão intracraniana e a pressão de perfusão cerebral, mas também parâmetros hemometabólicos cerebrais nestes pacientes gravemente enfermos. Normas ("guidelines") atualmente disponíveis para tratamento não são baseadas em evidência.

PALAVRAS-CHAVE: traumatismo cerebral, pressão intracraniana, pressão de perfusão cerebral, extração cerebral de oxigênio.

Over the past decade, conflicting information has been addressed with regard to research and management of severe acute brain trauma, so that heterogeneous standards for acute patient care have become apparent. With the exception of life-saving measures at the prehospital and emergency room levels, which are believed standardized in most developed and developing countries, diverse strategies have been reported in the intensive care unit setting.

This review is aimed at discussing and clarifying findings that have been reported in the pertinent international literature, as an attempt to guide neuroprofessionals toward better understanding clinical research and management propositions, insofar as neuro critical care is concerned.

\section{Intracranial pressure and cerebral hemometabolism}

In addition to the presence of acute intracranial lesions with mass effect (most of them promptly managed surgically), intracranial pressure (ICP) problems during intensive care have been frequently attributed to the presence of brain edema and subarachnoid hemorrhage. Despite ongoing research over the years, however, little is known about the influence of changes in cerebral blood volume $(\mathrm{CBV})$. Nevertheless, cerebral blood flow (CBF) is directly proportional to $\mathrm{CBV}$, and several studies have addressed variable $\mathrm{CBF}$ patterns during the acute phase of injury.

*Director, The Comprehensive International Center for Neuroemergencies and Post-Graduate Professor, Escola Paulista de Medicina, Federal University of São Paulo, São Paulo, Brazil. Aceite: 3-abril-2000.

Julio Cruz, M.D., Ph.D. - CICNEM - P.O. Box Cx. Postal 57011 - 04093-970 São Paulo SP - Brasil. Fax 551137410429. 
Perhaps the most informative paper from the $1980 \mathrm{~s}^{1}$ addressed a statistically significant association between cerebral hyperemia and intracranial hypertension, in contrast with predominantly reduced CBF during periods of normal ICP. In this latter report ${ }^{1}$, hyperemia was also described as normal CBF levels (in absolute values), which were nevertheless associated with decreased global cerebral oxygen extraction, as measured by the arteriojugular oxygen content difference $\left(\mathrm{AVDO}_{2}\right)$; that is, the finding of relative cerebral hyperperfusion with normal CBF was clear because cerebral oxygen consumption was pathologically reduced, and not only high but also normal CBF levels were associated with low oxygen extraction. From our findings ${ }^{1}$, global cerebral ischemia was essentially ruled out in severe acute brain trauma.

In contrast, the Richmond group ${ }^{2}$ later addressed a $33 \%$ rate of early global brain ischemia in 35 patients with severe acute brain trauma, during the first 6 hours after injury. However, despite $\mathrm{CBF}$ values in the low range, $\mathrm{AVDO}_{2}$ did not exceed the upper normal limit of $8.3 \mathrm{vol} \%{ }^{3}$ in any of the studied patients (Figure 1 of Bouma's paper ${ }^{2}$ ). Therefore, the true rate of "pre-ischemic" or "potentially ischemic" levels of cerebral oxygen extraction was zero percent. In contrast, starting at approximately 12 postinjury hours, relative cerebral hyperperfusion represented a general rule throughout the acute phase, as determined by $\mathrm{AVDO}_{2}$ values below the lower normal limit of 5.1 $\mathrm{vol}_{\%}^{3}$ (Table 1 of that paper ${ }^{2}$ ). Unlike our previous report ${ }^{1}$, in the Richmond series ${ }^{2}$ no emphasis was placed on ICP problems relative to $\mathrm{CBF}$ and $\mathrm{AVDO}_{2}$.

$\mathrm{We}^{4}$ later reported that $\mathrm{AVDO}_{2}$ is an unreliable parameter of cerebral oxygen extraction in either moderate or profound acute anemia, and proposed a new variable termed cerebral extraction of oxygen $\left(\mathrm{CEO}_{2}\right.$, the arteriojugular oxyhemoglobin saturation difference $\left.{ }^{4-8}\right)$. Moderate acute anemia is frequent during intensive care and is not managed under several circumstances. $\mathrm{AVDO}_{2}$ underestimates cerebral oxygen extraction while $\mathrm{CEO}_{2}$ does not. Therefore, $\mathrm{AVDO}_{2}$ overestimates cerebral hyperemia (unlike $\left.\mathrm{CEO}_{2}\right)^{4}$. Accordingly, therapeutic modalities for elevated ICP based on cerebral vasoconstriction (hyperventilation, dihydroergotamine, indomethacin, barbiturates, hypothermia, etc) can be optimized based on $\mathrm{CEO}_{2}$ more accurately than by $\mathrm{AVDO}_{2}$. The same applies to therapies that simultaneously lower the ICP and increase cerebral venous oxygenation and CBF, such as mannitol ${ }^{6}$.

\section{Cerebral perfusion pressure}

First proposed by Langfitt et al. ${ }^{9}$, cerebral perfusion pressure (CPP, the difference between mean arterial pressure and mean ICP) has been "re-visited" by Rosner et al. ${ }^{10}$. These latter authors have proposed managing acute brain trauma with the head flat, normocapnic throughout the acute phase, with induced arterial hypertension as a means of maintaining CPP above $70 \mathrm{~mm} \mathrm{Hg}$. Except for mannitol and cerebrospinal fluid drainage, none of the above-mentioned therapies was adopted in Rosner's experience ${ }^{10}$.

As described above, however, relative cerebral hyperperfusion (rather than ischemia) represents a general rule during most of the acute postinjury phase and, therefore, cerebral vasoconstrictive therapies are indicated, in addition to mannitol. Rosner's claim of improved clinical outcome ${ }^{10}$ was not valid because a control group was not evaluated. Rather, Rosner et al. ${ }^{10}$ calculated chi-square outcome statistics using their patient population against that of the American Traumatic Coma Data Bank. The two populations were not comparable, however, because in Rosner's series only 35\% of the patients had brain swelling, with a low $16 \%$ rate of compromised basilar cisterns, indicative of a less severe patient population than that of the coma bank.

A recent report ${ }^{11}$ involving over 400 patients has made it clear that CPP levels above $60 \mathrm{~mm}$ $\mathrm{Hg}$ are not associated with improved clinical outcome, and that intracranial hypertension (rather than CPP) is the most devastating phenomenon in association with poor outcome figures. Furthermore, Rosner's patients underwent an average 18-day of ICP and CPP monitoring (with a $29 \%$ mortality rate $)^{10}$, versus one week only (with a low $9 \%$ mortality rate) in our large series ${ }^{12}$ of over 350 prospectively evaluated, selected patients with high ICP and brain swelling, in whom therapeutic 
measures were adopted to normalize not only ICP and CPP, but also $\mathrm{CEO}_{2}$. Therefore, Rosner's proposal ${ }^{10}$ induces intracranial hypertension, with resulting ultra-prolonged monitoring and high mortality rate relative to the presence of acutely decreased cerebrospinal fluid spaces.

From the above discussion, "CPP management" totally ignores the natural history of cerebral hemodynamics and metabolism in severe acute brain trauma; that is, a state of initially reduced CBF normally coupled with reduced cerebral oxygen consumption, which is then followed by a prolonged, sustained pattern of relative cerebral hyperperfusion. Furthermore, $\mathrm{we}^{13}$ have also unequivocally demonstrated that normal-to-increased CPP holds absolutely no correlation with cerebral oxygen metabolism (both oxygen extraction and consumption), thus ruling out any beneficial effect of normalto-increased CPP levels ${ }^{13}$. Accordingly, "CPP management" as previously proposed ${ }^{10}$ involves more deleterious than beneficial effects both on intracranial dynamics and clinical outcome.

\section{Combined cerebral oxygen and glucose metabolism}

Back in 1995, we ${ }^{8}$ reported a state of global cerebral hypoglycolysis during near normocapnia (when ICP problems had subsided); that is, cerebral extraction of glucose was pathologically reduced relative to $\mathrm{CEO}_{2}$, a condition that markedly improved during optimized hyperventilation (which simultaneously normalized ICP, $\mathrm{CEO}_{2}$ and cerebral extraction of glucose) $)^{8}$.

In a later report, however, Bergsneider et al. ${ }^{14}$ addressed cerebral hyperglycolysis also during near normocapnia. This "hypermetabolic" condition, however, was a function of a methodological artifact, because the ratio of cerebral glucose to oxygen consumption was calculated using cortical glucose values against global oxygen measurements. Yet, it is well known that global metabolic values are far lower than cortical ones.

\section{Cerebral blood flow alone}

In the normal (awake) monkey brain ${ }^{15}$, ischemic CBF thresholds have been addressed at levels below $18 \mathrm{~mL} / 100 \mathrm{~g} / \mathrm{min}$. In comatose patients, however, cerebral oxygen consumption frequently falls by approximately $50 \%$ (or more) ${ }^{16}$. Accordingly, ischemic CBF thresholds in comatose patients are expectedly $50 \%$ lower than in the normal brain, or $9 \mathrm{~mL} / 100 \mathrm{~g} / \mathrm{min}^{17}$. Therefore, research involving regional or global CBF alone in comatose patients has emphatically overemphasized cerebral ischemia without the necessary concomitant metabolic data ${ }^{18-21}$. In this respect, regional CBF values as high as $40 \mathrm{~mL} / 100 \mathrm{~g} / \mathrm{min}$ have been proposed as "ischemic" in acute coma ${ }^{21}$, an approach that appears to be conceptually inadequate.

\section{Optimized versus indiscriminate hyperventilation}

Optimized hyperventilation has been proposed in our work ${ }^{7,8,12}$ as a means of not only normalizing ICP but also $\mathrm{CEO}_{2}$. By doing so, we have introduced intentional restoration of the clinically beneficial coupling between $\mathrm{CBF}$ and oxygen consumption. In this respect, a previous study by Jaggi et al. ${ }^{16}$ addressing observational (non interventional) research has disclosed better clinical outcome of patients when global cerebral oxygen extraction is spontaneously found within the normal range than when relative cerebral hyperperfusion (decreased oxygen extraction) exists during the acute postinjury phase.

In a recent prospective, controlled trial involving a large number of patients, we $\mathrm{e}^{12}$ have addressed statistically better clinical outcome figures in patients subjected to both moderate and profound optimized hyperventilation (based on $\mathrm{CEO}_{2}$ monitoring), than in the control group where only mild non optimized hyperventilation was adopted (because $\mathrm{CEO}_{2}$ monitoring was not adopted).

In contrast to the above findings, Muizelaar et al. ${ }^{22}$ have addressed adverse effects of hyperventilation, but in a small group of patients randomly assigned to hypocapnic treatment. In this latter report, however, only $14 \%$ of the patients had elevated ICP when hyperventilation was initially instituted (Table 1 of that paper $^{22}$ ). Accordingly, hyperventilation was contraindicated in as many as $86 \%$ of the randomized patients; that is, hyperventilation was used indiscriminately. These "adverse 
effects" were described as a "slowness" in neurologic recovery which, nevertheless, was no different from the control group at one year postinjury.

Because of the small number of patients in those randomized groups ${ }^{22}$, only 5-6 patients with more severe lesion types (e.g., diffuse axonal injury) could have well explained the observed "slowness" in neurologic recovery (typical of axonal injury), rather than an adverse effect of hyperventilation itself. Moreover, the mortality rate was $18 \%$ higher in non hyperventilated patients, which corresponds to approximately half the mortality rate reported by others ${ }^{1,10,23}$; that is, Muizelaar et al. ${ }^{22}$ did not hyperventilate patients at random even in the presence of elevated ICP and progressing signs of tentorial herniation (in order not to violate the randomization scheme) when, in fact, half of those who died could have been saved if hyperventilated.

As previously reported ${ }^{7,8}$, optimized hyperventilation presents with the very largest number of positive physiologic effects in comparison with any other treatment modality for acute brain injury with intracranial hypertension. These positive effects are as follows: 1) prompt normalization of elevated $\mathrm{ICP}^{7} ; 2$ ) normalization of decreased $\mathrm{CEO}_{2}$ (or relative hyperperfusion), thereby restoring normal coupling between $\mathrm{CBF}$ and oxygen consumption ${ }^{7}$; 3 ) normalization of pathologically decreased cerebral extraction of glucose $\left.{ }^{8} ; 4\right)$ restoration of normal coupling between cerebral oxygen and glucose extraction, thereby restoring normal cerebral aerobic metabolism ${ }^{8}$; 5) normalization of CPP without the need for vasopressor drugs $^{7,8}$; and 6) improvement or maintenance of adequate systemic hemodynamics and oxygenation ${ }^{7}$. These multiple positive physiologic effects explain the recently reported findings of improved clinical outcome in optimally hyperventilated patients in comparison with a control group ${ }^{12}$.

\section{Optimized mannitol}

Also based on $\mathrm{CEO}_{2}$ monitoring, optimization of mannitol administration has become possible ${ }^{6}$. In this latter report, we described a simultaneous decrease in elevated ICP and normalization of increased $\mathrm{CEO}_{2}$ (or cerebral oligemia). Accordingly, in light of these findings, mannitol cannot be optimized based on ICP measurements only ${ }^{6}$; that is, mannitol is not optimally administered when high ICP is associated with decreased $\mathrm{CEO}_{2}$ (relative hyperperfusion), because mannitol further increases CBF. This latter finding may explain a "rebound" effect, when ICP recurrently increases shortly after mannitol administration.

\section{Optimized barbiturate therapy}

Unlike optimized hyperventilation and mannitol ${ }^{6-8,12}$, barbiturate (pentobarbital) therapy has been reported in association with transiently decreased cerebral venous oxygenation in some patients with refractory $\mathrm{ICP}^{24}$. These undesired findings were addressed shortly following the intravenous bolus injections, when the blood pressure fell. Accordingly, a transient decrease in cerebral oxygenation to oligemic hypoxic levels may be observed following barbiturate boluses, even though no adverse effects have been found during prolonged barbiturate maintenance infusion.

\section{Additional therapies}

In light of the above-described findings, it is apparent that virtually all therapeutic modalities for elevated ICP may be optimized by $\mathrm{CEO}_{2}$ monitoring rather than by ICP and CPP only. This is particularly true because most therapies influence $\mathrm{CBF}$ and/or oxygen metabolism. Future studies will tell us more about that.

\section{Alternative monitoring modalities}

Stocchetti, et al. ${ }^{25}$ have proposed bilateral jugular monitoring, as they found side-to-side differences of up to $15 \%$. In their experience, however, continuous fiberoptic jugular monitoring was not carried out with strict immobilization of the patient's neck, so that much of their described differences may have been artifactual. This is because the fiberoptic jugular catheter may easily generate artifactual readings even with minor changes in head positioning. In light of improved 
clinical outcome from a large series of patients subjected to unilateral continuous fiberoptic jugular monitoring ${ }^{12}$, it is therefore apparent that bilateral jugular catheterization should not be considered.

Non invasive near infrared spectroscopy for mixed arteriolar and venular monitoring is being abandoned because, unlike the normal brain ${ }^{26}$, this technique fails to demonstrate large hypoxic changes in jugular oxyhemoglobin saturation in injured brains ${ }^{27}$. This limitation is probably because the technology assumes normal arteriolo-venular compartmental distribution in injured brain, which may not be true under several circumstances.

Highly invasive, acutely implanted probes into brain tissue have also been proposed for both tissue oxygen monitoring and evaluation of other elements by microdialysis ${ }^{28}$. In this respect, however, acutely implanted brain tissue probes (even the smallest ones) produce focal microvascular compression and distortion, besides blood-brain barrier alterations. Therefore, artifactual abnormalities such as low tissue oxygen and high tissue lactate may be found ${ }^{28}$, which may have no relationship with the rest of the brain that is not under mechanical load. Accordingly, it is also likely that brain tissue probes will soon be abandoned, at least by those who acknowledge their inherent technical limitations.

From the above discussion, unilateral jugular monitoring still represents the gold standard for bedside cerebral hemometabolic monitoring and management. For regional evaluation, however, $\mathrm{CBF}$ alone is not adequate, because concomitant metabolic information is always mandatory in injured brain. In this respect, out of the intensive care unit techniques are therefore required, such as positron emission tomography and/or functional magnetic resonance imaging. These two latter diagnostic modalities, however, are not suitable for acutely ill, unstable patients, to whom the intensive care unit still represents the most protective environment.

\section{GUIDELINES}

Back in 1996, guidelines for the management of severe acute brain trauma were reported and said to be evidence-based ${ }^{29}$. Those authors claimed that hyperventilation should be avoided and that normocapnic "CPP management" 10 should be adopted. As described above, however, optimized hyperventilation ${ }^{7,8}$ was reported before those guidelines were written. Because optimized hyperventilation provides the largest number of positive physiologic effects in comparison with any other therapeutic modality ${ }^{7,8}$, it then becomes clear that those guidelines ${ }^{29}$ are not evidence-based.

Furthermore, normocapnic "CPP management"10 is contraindicated in patients with acutely decreased cerebrospinal fluid spaces under most circumstances, as outlined above. As of 1998, combined management of ICP, CPP and $\mathrm{CEO}_{2}$ by optimized hyperventilation (besides other therapies) has been clearly reported in association with improved clinical outcome ${ }^{12}$. It therefore remains for future, alternative guidelines to fully cover the pertinent literature in an unbiased fashion, so that true evidence-based information may become available to those involved in neuro critical care medicine.

\section{REFERENCES}

1. Obrist WD, Langfitt TW, Jaggi JL, Cruz J, Gennarelli TA. Cerebral blood flow and metabolism in comatose patients with acute head injury: relationship to intracranial hypertension. J Neurosurg 1984;61:241-253.

2. Bouma GJ, Muizelaar JP, Choi SC, Newlon PG, Young HF. Cerebral circulation and metabolism after severe traumatic brain injury: the elusive role of ischemia. J Neurosurg 1991;75:685-693.

3. Gibbs EL, Lennox WG, Nims LF, Gibbs FA. Arterial and cerebral venous blood: arterial-venous differences in man. J Biol Chem 1942;144:325-332.

4. Cruz J, Jaggi JL, Hoffstad OJ. Cerebral blood flow and oxygen consumption in acute brain injury with acute anemia: an alternative for the cerebral metabolic rate of oxygen consumption ? Crit Care Med 1993;21:1218-1224.

5. Cruz J. Continuous versus serial global cerebral hemometabolic monitoring: applications in acute brain trauma. Acta Neurochir (Suppl) 1988;42:35-39.

6. Cruz J, Miner ME, Allen SJ, Alves WM, Gennarelli TA. Continuous monitoring of cerebral oxygenation in acute brain injury: injection of mannitol during hyperventilation. J Neurosurg 1990;73:725-730.

7. Cruz J. Combined continuous monitoring of systemic and cerebral oxygenation in acute brain injury: preliminary observations. Crit Care Med 1993;21:1225-1232.

8. Cruz J. An additional therapeutic effect of adequate hyperventilation in severe acute brain trauma: normalization of cerebral glucose uptake. J Neurosurg 1995;82:379-385. 
9. Langfitt TW, Weinstein JD, Kassell NF. Cerebral vasomotor paralysis produced by intracranial hypertension. Neurology 1965;15:622-641.

10. Rosner MJ, Rosner SD, Johnson AH. Cerebral perfusion pressure: management protocol and clinical results. J Neurosurg 1995;83:949-962.

11. Juul N, Morris GF, Marshall SB, The Executive Committee of the International Selfotel Trial, Marshall LF. Intracranial hypertension and cerebral perfusion pressure: influence on neurological deterioration and outcome in severe head injury. $\mathbf{J}$ Neurosurg 2000;92:1-6.

12. Cruz J. The first decade of continuous monitoring of jugular bulb oxyhemoglobin saturation: management strategies and clinical outcome. Crit Care Med 1998;26:344-351.

13. Cruz J, Jaggi JL, Hoffstad OJ. Cerebral blood flow, vascular resistance, and oxygen metabolism in acute brain trauma: redefining the role of cerebral perfusion pressure ? Crit Care Med 1995;23:1412-1417.

14. Bergsneider M, Hovda DA, Shalmon E, et al. Cerebral hyperglycolysis following severe traumatic brain injury in humans: a positron emission tomography study. J Neurosurg 1997;86:241-251.

15. Jones TH, Morawetz RB, Crowell RM, et al. Thresholds of focal cerebral ischemia in awake monkeys. J Neurosurg 1981;54:773-782.

16. Jaggi JL, Obrist WD, Gennarelli TA, Langfitt TW. Relationship of early cerebral blood flow and metabolism to outcome in acute head injury. J Neurosurg 1990;72:176-182.

17. Cruz J. Low clinical ischemic threshold for cerebral blood flow in severe acute brain trauma: case report. J Neurosurg 1994;80:143-147.

18. Marion DW, Darby J, Yonas H. Acute regional cerebral blood flow changes caused by severe head injuries. J Neurosurg 1991;74:407-414.

19. Bouma GJ, Muizelaar JP, Stringer WA, Choi SC, Fatouros P, Young HF. Ultra-early evaluation of regional cerebral blood flow in severely head-injured patients using xenon-enhanced computerized tomography. J Neurosurg 1992;77:360-368.

20. Schroder ML, Muizelaar JP, Kuta AJ. Documented reversal of global ischemia after removal of an acute subdural hematoma. J Neurosurg 1994;80:324-327.

21. Ritter AM, Muizelaar JP, Barnes T, et al. Brain stem blood flow, pupillary response, and outcome in patients with severe head injuries. Neurosurgery 1999;44:941-948.

22. Muizelaar JP, Marmarou AM, Ward JD, et al. Adverse effects of prolonged hyperventilation in patients with severe head injury: a randomized clinical trial. J Neurosurg 1991;75:731-739.

23. Marshall LF, Maas AIR, Marshall SB, et al. A multicenter trial on the efficacy of using tirilazad mesylate in cases of head injury. J Neurosurg 1998;89:519-525.

24. Cruz J. Adverse effects of pentobarbital on cerebral venous oxygenation of comatose patients with severe traumatic brain swelling: relationship to outcome. J Neurosurg 1996;85:758-761.

25. Stocchetti N, Paparella A, Bridelli F, et al. Cerebral venous oxygen saturation studies with bilateral samples in the internal jugular veins. Neurosurgery 1994;34:38-44.

26. McCormick P, Stewart M, Goetting M, et al. Noninvasive cerebral optical spectroscopy for monitoring cerebral oxygen delivery and hemodynamics. Crit Care Med 1991;19:89-97.

27. Lewis SB, Myburgh JA, Thornton EL, et al. Cerebral oxygenation monitoring by near-infrared spectroscopy is not clinically useful in patients with severe closed-head injury: a comparison with jugular venous bulb oximetry. Crit Care Med 1996;24:1334-1338.

28. Menzel M, Doppenberg EMR, Zauner A, Soukup J, Reinert MM, Bullock R. Increased inspired oxygen concentration as a factor in improved brain tissue oxygenation and tissue lactate levels after severe human head injury. J Neurosurg 1999;91:1-10.

29. Bullock R, Chesnut RM, Clifton G, et al. Guidelines for the management of severe head injury. J Neurotrauma 1996;13:639-734. 